\title{
Pharmacological Evaluation of Stem Bark of Callicarpa arborea Roxb.
}

\author{
Mahbubul Hoque Shihan, Zobaer Al Mahmud, Nazmul Qais and Mohammad Riaz
}

Department of Clinical Pharmacy and Pharmacology, Faculty of Pharmacy, University of Dhaka Dhaka-1000, Bangladesh

Received: April 08, 2015; Accepted: June 08, 2015; Published (web): June 15, 2015

\begin{abstract}
The ethanol extract of stem bark of Callicarpa arborea and its different fractions were investigated for various pharmacological properties. In the acetic acid-induced writhing inhibition assay, the ethanol extract and its chloroform and ethyl acetate soluble fractions at a dose of $200 \mathrm{mg} / \mathrm{kg}$ body weight significantly inhibited writhing response with $42.7 \%, 70.3 \%$ and $32.8 \%$ of inhibition, respectively. In the antioxidant assay by DPPH, the ethanol extract and its pet ether and chloroform soluble partitionates demonstrated significant free radical scavenging activity with $\mathrm{IC}_{50}$ values of $41.53,14.59$ and $71.2 \mu \mathrm{g} / \mathrm{mL}$, respectively. In the disc diffusion method, the carbon tetrachloride soluble materials showed potential antimicrobial activity against all the tested organisms with zone of inhibition ranging from 19-22 $\mathrm{mm}$ at a concentration of $400 \mu \mathrm{g} / \mathrm{disc}$. On the other hand, the pet ether soluble fraction induced significant clot lysis $(30.43 \%)$ when compared to negative control. Our findings from the studies clearly indicate that the stem bark of C. arborea possesses potential antinociceptive, antioxidant, antimicrobial and thrombolytic activities, which further warrant its systematic chemical investigation in order to isolate the biologically active molecules.
\end{abstract}

Key words: Callicarpa arborea, stem bark, ethanol extract, analgesic, antioxidant, antimicrobial, clot lysis

\section{INTRODUCTION}

In spite of the great advancements observed in modern medicines in recent decades, plants still make an important contribution to health care. ${ }^{1}$ Over the past decades, interest in drugs derived from higher plants, especially the phytotherapeutic ones, has increased expressively. ${ }^{2}$ Callicarpa arborea Roxb. is a shrub or tree, which traditionally belongs to the family Verbenaceae. It grows well in different environments and mainly found in Bangladesh, China, India, Indonesia, Nepal, Papua New Guinea, Thailand, United States and Vietnam. ${ }^{3}$ Ethnobotanical reports indicate the use of the bark of this plant in the treatment of fever and indigestion ${ }^{4,5}$ in Nepal and skin diseases in India. ${ }^{6}$ Plant extract is anti-inflammatory in rats. ${ }^{3}$ Paste of the bark and juice of C. arborea have been used by the tribals of Mizoram to cure cuts and wounds. ${ }^{7}$ Previous studies

Correspondence to: Zobaer Al Mahmud

Tel: +880-1722597925; Fax: +880-2-9667222

E-mail: zalmahmud@du.ac.bd

Dhaka Univ. J. Pharm. Sci. 14(1): 111-116, 2015 (June) revealed that the bark of the plant contains bauerenol, $\beta$-sitosterol and betulinic acid ${ }^{6}$ while the leaves contain $\beta$-sitosterol, epilupeol, ursolic acid. ${ }^{8}$ Although the bark of the plant has been traditionally used in the treatment of various painful and antiinflammatory conditions, and infectious disease there is no reports on the anti-nociceptive, antimicrobial and other bioactivity studies of this valuable medicinal plant to significant level. Therefore the present study was designed to check the ethonomedicinal claims as well as to evaluate the antinociceptive, antioxidant, antimicrobial, cytotoxic and thrombolytic activities of the ethanolic extract of the bark of C. arborea for the first time.

\section{MATERIALS AND METHODS}

Collection and extraction of plant material. Stem bark of C. arborea was collected in June, 2010 from the Dhaka University campus, Bangladesh and identified by the botanist of Department of Botany, University of Dhaka. The collected plant materials 
were chopped, dried and powdered and 900 gm was extracted with 3.5 liters of ethanol at room temperature for 7 days. The extract were filtered through Whatman filter paper number 1 and concentrated with a rotary evaporator at reduced temperature and pressure. A portion of the concentrated ethanol extract (EECA,10.0 gm) was fractionated by the modified Kupchan partitioning protocol $^{9,10}$ into pet-ether (PEFCA, $3.5 \mathrm{gm}$ ), carbon tetrachloride (CTFCA, $2.0 \mathrm{gm}$ ), chloroform (CFFCA, $0.8 \mathrm{gm}$ ), ethyl acetate (EAFCA, $1.5 \mathrm{gm}$ ) and aqueous (AQFCA, $0.42 \mathrm{gm}$ ) soluble materials.

Chemicals and reagents. The chemicals used were acetic acid (Merck, Germany), diclofenac sodium and ciprofloxacin (Square Pharmaceuticals Ltd., Dhaka, Bangladesh), normal saline solution $(0.9 \% \mathrm{NaCl}$; Orion Infusion Ltd., Bangladesh), DPPH (Merck, Germany), streptokinase (Beacon Pharmaceuticals, Dhaka, Bangladesh). Dimethylsulfoxide and Tween-80 were from Sigma Aldrich and rests of the chemicals used were from BDH and E-Merck (analytical grade).

Experimental animals. Swiss-Albino mice (Mus musculus) of either sex (aged 4-5 weeks, 20-25 gm body weight) were collected from the Animal Resource Branch of the International Center for Diarrhoeal Diseases and Research, Bangladesh (ICDDR,B). The animals were housed in the standard polypropylene cages $(30 \times 20 \times 13 \mathrm{~cm})$ and kept under standard laboratory conditions (relative humidity $55-60 \%$, room temperature $23 \pm 2{ }^{\circ} \mathrm{C}$ and 12 hours light/dark cycle) for 14 days prior to performing the experiments. They were given ICDDR,B supplied standard diet and water ad libitum.

Acetic acid-induced writhing response in mice. The ethanol extract of stem bark of C. arborea and its different partitioning fractions were subjected to screening for analgesic activity by acetic acid induced writhing inhibition method. ${ }^{11}$ Initially, 40 Swiss albino mice were divided into eight groups $(\mathrm{n}=5)$. Subsequently, vehicle ( $1 \%$ Tween- 80 solution in normal saline, $10 \mathrm{~mL} / \mathrm{kg}$, as negative control), diclofenac sodium (50 mg/kg, as standard), ethanolic crude extract (100 and $200 \mathrm{mg} / \mathrm{kg}$ ), $\mathrm{CCl}_{4}$, chloroform and ethyl acetate fractions of ethanolic extract $(200$ $\mathrm{mg} / \mathrm{kg}$ ) dispersed in normal saline containing $1 \%$ Tween-80 were administered orally. After 40 minutes, acetic acid $(0.7 \%, 0.1 \mathrm{~mL} / 10 \mathrm{gm})$ was administered intra-peritoneally to each of the animals. Five minutes after the administration of acetic acid, each mouse was taken in an individual observation chamber and the cumulative number of writhing responses was recorded for $15 \mathrm{~min}$. Percentage inhibition of writhing compared to control group was taken as an index of analgesia and was calculated using the following formula:

Inhibition $(\%)=[(\mathrm{Wc}-\mathrm{Wt}) \times 100] / \mathrm{Wc}$

where, $\mathrm{Wc}$ is the average number of writhing reflex in the control group and $\mathrm{Wt}$ is the average number of writhing in the test groups.

DPPH radical scavenging assay, The free radical scavenging activity of the plant extractives on the stable radical 1,1-diphenyl-2-picrylhydrazyl (DPPH) was determined by the method established by Brand-Williams. ${ }^{12}$ Inhibition of free radical DPPH in percent (I \%) was calculated as follows:

$$
(\mathrm{I} \%)=\left(1-\mathrm{A}_{\text {sample }} / \mathrm{A}_{\text {blank }}\right) \times 100
$$

where, $A_{\text {blank }}$ is the absorbance of the control reaction (containing all reagents except the test material), and $\mathrm{A}_{\text {sample }}$ is the absorbance of the test sample.

In vitro antimicrobial screening. The in vitro antimicrobial activities of the test samples were determined by the disc diffusion method. ${ }^{13}$

Thrombolytic activity. The thrombolytic activity of all extractives was evaluated by the in vitro clot lysis model described by Prasad et al., ${ }^{14}$ using streptokinase as a standard. Here each of the concentrated extract (100 mg) was suspended in 10 $\mathrm{mL}$ of distilled water and it was kept overnight. Then the soluble supernatant was decanted and filtered through Whatman filter paper number 1 . Aliquots (7 $\mathrm{mL}$ ) of venous blood were drawn from healthy volunteers $(n=20)$ without a history of oral contraceptive or anticoagulant therapy which were distributed in seven different pre-weighed sterile microcentrifuge tube (1 mL/tube) and incubated at 37 
${ }^{\circ} \mathrm{C}$ for 45 minutes. After clot formation, the serum was completely removed and each tube was again weighed to determine the clot weight. To each microcentrifuge tube, $100 \mu \mathrm{l}$ aqueous solution of different partitionates along with the crude extract was added separately. Then $100 \mu \mathrm{l}$ of streptokinase (30 000 I.U) and $100 \mu \mathrm{l}$ of distilled water were separately added to the control tubes as positive and negative control, respectively. All the tubes were then incubated at $37^{\circ} \mathrm{C}$ for 90 minutes and observed for clot lysis. After the incubation period, the released fluid was removed and tubes were again weighed. The differences in weights taken before and after clot lysis were expressed as percentage of clot lysis as shown below:

$\%$ of clot lysis $=($ wt of released clot $/$ clot wt $) \times 100$

\section{RESULTS AND DISCUSSION}

In this study we evaluated the anti-nociceptive, antioxidant, anti-microbial, and thrombolytic activities of ethanolic extracts obtained from the stem barks of C. arborea and its different fractions using acetic acid-induced writhing in mice, DPPH radical scavenging assay, in vitro disc diffusion method, and in vitro clot lysis model, respectively. At the dose of $200 \mathrm{mg} / \mathrm{kg}$ body weight p.o. the ethanolic extract of bark of C. arborea (EECA) and its chloroform soluble fraction (CHFCA) produced a significant $(p<0.001)$ reduction in the number of writhing by
$42.7 \%$ and $70.3 \%$, respectively when compared to the control group (Table 1). The analgesic potential of CHFCA was even higher than that of the standard drug diclofenac sodium (64.9\% inhibition compared to control; $p<0.001)$. The ethyl acetate soluble fraction (EAFCA) also significantly $(p<0.001)$ produced $32.8 \%$ writhing inhibition at the same dose. Previous studies have shown that acetic acid acts indirectly by inducing the release of endogenous mediators of pain such as prostaglandins, histamine, serotonin (5-HT), bradykinin and substance $\mathrm{P}^{15,16}$ that stimulate the nociceptive neurons which are sensitive to non-steroidal anti-inflammatory drugs and opioids. ${ }^{17}$ Hence, the peripheral antinociception exhibited by the extractives may be related to inhibition of the release of endogenous nociceptive mediators especially the inhibition of prostaglandin synthesis, since the nociceptive mechanism of abdominal writhing induced by acetic acid involves the process of release of arachidonic acid metabolites via COX (cyclooxygenase) and prostaglandin biosynthesis. ${ }^{18}$ The bark of C. arborea contains terpenoids (bauerenol, betulinic acid etc.) and steroid ( $\beta$-sitosterol), and the analgesic activities showed by the plant extracts may be due to the presence of these compounds as terpenoids ${ }^{19}$ and steroidal compounds $^{20,21}$ have been reported to possess good analgesic activity by inhibiting prostaglandin synthesis.

Table 1. Effect of ethanolic crude extract and its different fractions of $C$. arborea bark against acetic acid-induced writhing in mice.

\begin{tabular}{lccc}
\hline Treatments & Dose $(\mathrm{mg} / \mathrm{kg})$ & Writhing $^{\mathrm{a}}$ & \% inhibition \\
\hline Control (vehicle) & $10 \mathrm{~mL} / \mathrm{kg}$ & $26.2 \pm 1.40$ & - \\
Diclofenac sodium & 50 & $9.2 \pm 0.97^{*}$ & 64.9 \\
EECA & 100 & $22.4 \pm 1.63$ & 14.9 \\
EECA & 200 & $15 \pm 0.95^{*}$ & 42.7 \\
PEFCA & 200 & $22.8 \pm 1.40$ & 12.9 \\
CTFCA & 200 & $25 \pm 1.14$ & 4.6 \\
CHFCA & 200 & $7.8 \pm 1.15^{*}$ & 70.3 \\
EAFCA & 200 & $17.6 \pm 1.63^{*}$ & 32.8 \\
\hline
\end{tabular}

a values represent mean \pm SEM $(n=5)$. $* p<0.001$ (One-way ANOVA followed by Dunnett's $t$ test, significantly different from control. EECA: ethanolic extracts of bark of C. arborea; PEFCA: petroleum ether fraction of ethanolic extract of bark of C. arborea; CTFCA: carbon tetrachloride fraction of ethanolic extract of bark of C. arborea; CHFCA: chloroform fraction of ethanolic extract of bark of $C$. arborea; EAFCA: ethyl acetate fraction of ethanolic extract of bark of C. arborea. 
The results of the DPPH free radical scavenging assay of the ethanolic extract of C. arborea bark (EECA) and its different fractions are shown in table 2 and figure 1. Compared to standard BHT $\left(\mathrm{IC}_{50}=\right.$ $71.02 \mu \mathrm{g} / \mathrm{ml}$ ), the ethanolic extract and its pet ether and chloroform soluble fractions revealed significant free radical scavenging activity with $\mathrm{IC}_{50}$ value of $41.53,14.59$ and $71.2 \mu \mathrm{g} / \mathrm{mL}$, respectively. The antioxidative characteristics might be attributed to the presence of phytochemicals such as terpenoids and steroids as previously reported..$^{22,23}$
Table 2. Free radical scavenging assay of $C$. arborea bark extractives and standard.

\begin{tabular}{ll}
\hline Test samples & $\mathrm{IC}_{50}$ values $(\mu \mathrm{g} / \mathrm{ml})$ \\
\hline BHT & 71.02 \\
EECA & 41.53 \\
PEFCA & 14.59 \\
CTFCA & 133.6 \\
CHFCA & 71.2 \\
EAFCA & 150.33
\end{tabular}

BHT: butylated hydroxyl toluene. EECA: ethanolic extracts of bark of C. arborea; PEFCA: petroleum ether fraction of ethanolic extract of bark of C. arborea; CTFCA: carbon tetrachloride fraction of ethanolic extract of bark of C. arborea; CHFCA: chloroform fraction of ethanolic extract of bark of C. arborea; EAFCA: ethyl acetate fraction of ethanolic extract of bark of $C$. arborea.

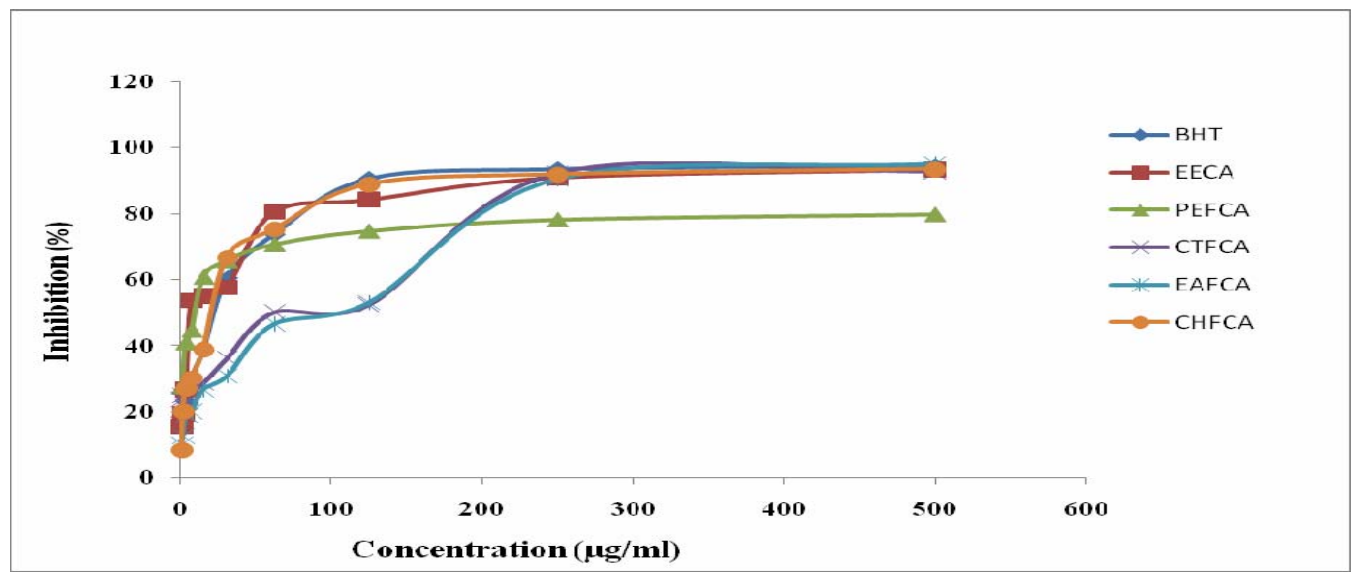

Figure 1. DPPH radical scavenging activity of ethanolic extracts of bark (EECA) and its different fractions at different concentrations. BHT: butylated hydroxyl toluene. PEFCA: petroleum ether fraction of ethanolic extract of bark of C. arborea; CTFCA: carbon tetrachloride fraction of ethanolic extract of bark of C. arborea; CHFCA: chloroform fraction of ethanolic extract of bark of C. arborea; EAFCA: ethyl acetate fraction of ethanolic extract of bark of C. arborea.

The CTFCA exhibited potential antimicrobial activity against all the test organisms with zone of inhibition ranging from $19-22 \mathrm{~mm}$ at $400 \mu \mathrm{g} / \mathrm{disc}$ (Table 3). The EECA, PEFCA and CHFCA also showed mild antimicrobial activity against all the test microorganisms where zone of inhibition produced were ranged from 10-12, 9-11 and 8-10 mm, respectively. The antimicrobial activity displayed by CTFCA may be attributed to the presence of bauerenol, betulinic acid and $\beta$-sitosterol as previously pentacyclic triterpenoids betulinic acid and related triterpenes ${ }^{24}$ and steroids such as $\beta$ sitosterol $^{25,26}$ have been reported to possess antimicrobial activity. Thus, the CTFCA extract may be a potential source of new anti-infective agents.
In this study we also examined the thrombolytic potential of ethanolic extract of bark of C. arborea and its different fractions using human blood. The results showed (Table 4), for the first time that the pet ether soluble fraction of ethanolic extract possesses significant $(p<0.001)$ thrombolytic activity $(30.43 \%$ clot lysis) indicating the possibility of developing novel thrombolytic agent(s) from the bark of this plant. The ethanolic extract and its carbon tetrachloride and ethyl acetate soluble fractions exhibited moderate thrombolytic activity with 23.53 , 23.40 and $23.53 \%$ clot lysis, respectively when compared to negative control. 
The results of the present study revealed that the stem bark of $C$. arborea possesses potential antinociceptive, antioxidant, antimicrobial, and thrombolytic activities. These results validated the traditional use of the plant parts in the treatment of various painful conditions, and infectious diseases. Further studies are required to establish the mechanism of action of these activities and to isolate and characterize the compounds responsible for such biological activities.

Table 3. Antimicrobial activity of test samples of $C$. arborea and ciprofloxacin.

\begin{tabular}{|c|c|c|c|c|c|c|}
\hline \multirow[t]{2}{*}{ Test organisms } & \multicolumn{6}{|c|}{ Diameter of zone of inhibition $(\mathrm{mm})$} \\
\hline & EECA & PEFCA & CTFCA & CHFCA & EAFCA & Ciprofloxacin \\
\hline \multicolumn{7}{|l|}{ Gram positive bacteria } \\
\hline Bacillus cereus & 12 & 10 & 20 & 10 & - & 47 \\
\hline B. megaterium & 11 & 9 & 19 & 9 & - & 47 \\
\hline B. subtilis & 11 & 10 & 19 & 9 & - & 46 \\
\hline Sarcina lutea & 10 & 10 & 20 & 8 & - & 47 \\
\hline Staphylococcus aureus & 10 & 10 & 20 & 8 & - & 46 \\
\hline \multicolumn{7}{|l|}{ Gram negative bacteria } \\
\hline Escherichia coli & 10 & 10 & 20 & 10 & - & 45 \\
\hline Pseudomonas aeruginosa & 10 & 10 & 20 & 10 & - & 46 \\
\hline Salmonella paratyphi & 10 & 10 & 19 & 10 & - & 47 \\
\hline S. typhi & 11 & 10 & 19 & 8 & - & 47 \\
\hline Shigella boydii & 11 & 10 & 19 & 8 & - & 47 \\
\hline Sh. dysenteriae & 11 & 10 & 19 & 8 & - & 46 \\
\hline Vibrio mimicus & 11 & 10 & 20 & 8 & - & 45 \\
\hline V. parahemolyticus & 10 & 10 & 21 & 8 & - & 45 \\
\hline \multicolumn{7}{|l|}{ Fungi } \\
\hline Aspergillus niger & 12 & 11 & 22 & 9 & - & 40 \\
\hline Candida albicans & 12 & 11 & 22 & 9 & - & 42 \\
\hline Sacharomyces cerevisiae & 12 & 11 & 22 & 9 & - & 45 \\
\hline
\end{tabular}

(-): No inhibition. EECA: ethanolic extracts of bark of C. arborea; PEFCA: petroleum ether fraction of ethanolic extract of bark of $C$. arborea; CTFCA: carbon tetrachloride fraction of ethanolic extract of bark of C. arborea; CHFCA: chloroform fraction of ethanolic extract of bark of C. arborea; EAFCA: ethyl acetate fraction of ethanolic extract of bark of C. arborea.

Table 4. Effect of ethanolic extract of bark of $C$. arborea and its different fractions on in vitro clot lysis of human blood.

\begin{tabular}{lccc}
\hline Test material & Concentration & $\mathrm{n}$ & $\%$ of blood clot lysis \\
\hline Distilled water & & 20 & $8.11 \pm 0.81$ \\
Streptokinase & $30,000 \mathrm{I} . \mathrm{U}$. & 20 & $65 \pm 2.03^{*}$ \\
EECA & $10 \mathrm{mg} / \mathrm{ml}$ & 20 & $23.53 \pm 2.36^{*}$ \\
PEFCA & $10 \mathrm{mg} / \mathrm{ml}$ & 20 & $30.43 \pm 3.96^{*}$ \\
CTFCA & $10 \mathrm{mg} / \mathrm{ml}$ & 20 & $23.40 \pm 3.70^{*}$ \\
CHFCA & $10 \mathrm{mg} / \mathrm{ml}$ & 20 & $14.89 \pm 4.06$ \\
EAFCA & $10 \mathrm{mg} / \mathrm{ml}$ & 20 & $23.53 \pm 2.06^{*}$ \\
\hline
\end{tabular}

${ }^{a}$ Values are mean $\pm \mathrm{SEM} ;{ }^{*} p<0.05$ (one-way ANOVA with Dunnett's $t$ test), significantly different from control. EECA: ethanolic extracts of bark of C. arborea; PEFCA: petroleum ether fraction of ethanolic extract of bark of C. arborea; CTFCA: carbon tetrachloride fraction of ethanolic extract of bark of $C$. arborea; CHFCA: chloroform fraction of ethanolic extract of bark of C. arborea; EAFCA: ethyl acetate fraction of ethanolic extract of bark of C. arborea.

\section{REFERENCES}

1. Calixto, J.B., Beirith, A., Ferreira, J., Santos, A.R., Cechinel, F.V. and Yunes, R.A. 2000. Naturally occurring antinociceptive substances from plants. Phytother. Res. 14, 401-418.
2. Calixto, J.B. 2000. Efficacy, safety, quality control, marketing and regulatory guidelines for herbal medicines (phytotherapeutic agents). Braz. J. Med. Biol. Res. 33, 179189. 
3. Asolkar, L.V., Kakkar, K.K. and Chakra, O.J. 1992. Second supplement to glossary of Indian medicinal plants with active principles Part-1 (A-K). NISC, CSIR, New Delhi, India, p. 265-266.

4. Manandhar, N.P. 1993. Herbal remedies of Surkhet district, Nepal. Fitoterapia 64, 266-272.

5. Manandhar, N.P. 1995. An inventory of some vegetable drug resources of Makawanpur district Nepal. Fitoterapia 66, 231238 .

6. Sen, M. and Pal, B.C. 1974. Chemical investigation of the bark of Callicarpa arborea (Verbenaceae). J. Indian Chem. Soc. 51, 903 .

7. Bhakuni, D.S., Dhar, M.L., Dhar, M.M., Dhawan, B.N., Gupta, B. and Srimal, R.C. 1971. Screening of Indian plants for biological activity. Part III. Indian J. Exp. Biol. 9, 91-102.

8. Sen, M. and Sarkar, U. 1978. Chemical investigation of the leaves of Callicarpa arborea (Verbenaceae). J. Indian. Chem. Soc. 55, 744-745.

9. Kupchan, S.M. and Tsou, G. 1973. Bruceantin. A new potent antileukemic simaroubolide from Brucea antidysenterica. J. Org. Chem. 38, 178-179.

10. VanWagenen, B.C., Larsen, R., Cardellina, J.H. II, Randazzo, D., Lidert, Z.C. and Swithenbank, C. 1993. Ulosantoin. a potent insecticide from the sponge Ulosa ruetzleri. J. Org. Chem. 58, 335-337.

11. Koster, R., Anderson, M. and Beer, E.J. 1959. Acetic acid for analgesic screening. Fed. Proc. 18, 412-416.

12. Brand, W., Cuvelier, W. and Berset, C. 1995. Use of free radical method to evaluate antioxidant activity. Lebensm. Wiss. Technol. 28, 25-30.

13. Bauer, A.W., Kirby, W.M., Sherris, J.C. and Turck, M. 1966. Antibiotic susceptibility testing by standardized single disc method. Am. J. Clin. Pathol. 45, 493-496.

14. Prasad, S., Kashyap, R.S., Deopujari, J.Y., Purohit, H.J., Taori, G.M. and Daginawala, H.F. 2006. Development of an in vitro model to study clot lysis activity of thrombolytic drugs. Thromb. J. 4, 1-4.

15. Collier, H.O., Dinneen, L.C., Johnson, C.A. and Schneider, C. 1968. The abdominal constriction response and its suppression by analgesic drugs in the mouse. Br. J. Pharmacol. 32, 295-310.
16. Deraedt, R., Jougney, S., Delevalcee, F. and Falhout, M. 1980. Release of prostaglandin $\mathrm{E}$ and $\mathrm{F}$ in an algogenic reaction and its inhibition. Eur. J. Pharmacol. 61, 17-24.

17. Sanchez-Mateo, C.C., Bonkanka, C.X., Hernandez-Perez, M. and Rabanal, R.M. 2006. Evaluation of the analgesic and topical anti-inflammatory effects of Hypericum reflexum L. fil. J. Ethnopharmacol. 107, 1-6.

18. Basbaum, A.I. and Julius, D. 2001. Molecular mechanisms of nociception. Nature 413, 203-210.

19. Margarita, H.P. and Rosa, M.R. 2002. Evaluation of the antiinflammatory and analgesic activity of Sideritis canariensis var. pannosa in mice. J. Ethnopharmacol. 81, 43-47.

20. Ramaswamy, S., Pillai, N.P., Gopalkrishnan, V., Parmar, N.S and Ghosh, M.N. 1985. Analgesic effect of O-( $\beta$ hydroxyethyl) rutoside in mice. Indian J. Exp. Biol. 23, 219220.

21. Ramadan, A., Harraz, F.M. and EI-Mougy, S.A. 1994. Antiinflammatory, analgesic and antipyretic effects of the fruit pulp of Adansonia digitata. Fitoterapia 65, 418-422.

22. Grassmann, J. 2005. Terpenoids as plant antioxidants. Vitam. Horm. 72, 505-535.

23. Rajanandh, M.G. and Kavitha, J. 2010. Quantitative estimation of $\beta$-sitosterol, total phenolic and flavonoid compounds in the leaves of Moringa oleifera. Int. J. Pharm. Tech. Res. 2, 14091414 .

24. Chung, P.Y., Parasakthi, N. and Chung, L.Y. 2011. Synergistic antimicrobial activity between pentacyclic triterpenoids and antibiotics against Staphylococcus aureus strains. Ann. Clin. Microbiol. Antimicrob. 10, 1-6.

25. Hess, S.C., Brum, R.L., Honda, N.K., Cruz, A.B., Moretto, E., Cruz, R.B., Messana, I.F., Filho, V.C. and Yunes, R.A. 1995. Antibacterial activity and phytochemical analysis of Vochysia divergens (Vochysiaceae). J. Ethnopharmacol. 47, 97-100.

26. Flavio, L.B., Greisiele, L.P., Dani, L.D., Benedito, P.D., Roberto B.B. and Diógenes, A.G. 2002. Evaluation of the antidiabetic and antibacterial activity of Cissus sicyoides. Braz. Arch. Biol. Technol. 45, 21-25. 